WSRC-TR-2007-00200

Keywords: Radiolysis, Hydrogen

\title{
Evaluation of Radiolysis-Induced Hydrogen Generation in DOT 6M Drums from INTEC
}

\author{
Savannah River National Laboratory
}

Materials Science and Technology

Publication Date: June 2007

\section{Washington Savannah River Company Savannah River Site Aiken, SC 29808}

This document was prepared in connection with work done under Contract No. DE-AC09-96SR18500 with the U. S. Department of Energy 


\section{DISCLAIMER}

This report was prepared as an account of work sponsored by an agency of the United States Government. Neither the United States Government nor any agency thereof, nor any of their employees, makes any warranty, express or implied, or assumes any legal liability or responsibility for the accuracy, completeness, or usefulness of any information, apparatus, product, or process disclosed, or represents that its use would not infringe privately owned rights. Reference herein to any specific commercial product, process, or service by trade name, trademark, manufacturer, or otherwise does not necessarily constitute or imply its endorsement, recommendation, or favoring by the United States Government or any agency thereof. The views and opinions of authors expressed herein do not necessarily state or reflect those of the United States Government or any agency thereof. 
DOCUMENT: WSRC-TR-2007-00200

TITLE: $\quad$ Evaluation of Radiolysis-Induced Hydrogen Generation in DOT 6M Drums from INTEC

\section{APPROVALS}

D. W. Vinson, Author

Date:

SRNL-Materials Science and Technology

N. E. Bibler, Technical Review

Date:

SRNL-Process Science and Engineering Section

N. M. Askew, Technical Review

Date:

SRNL-Actinide Sciences Programs

R. L. Sindelar, Manager

Date:

SRNL-Materials Science and Technology

Date:

N. C. Iyer, Director

SRNL-Materials Science and Technology

J. Bodkin, Customer

Date:

SFP-SFP Operations Engineering

T. J. Spieker, Manager

Date:

SFP-SFP Operations Engineering

R. W. Watkins

Date:

HMD-HB-Line Ph II Engineering 


\section{Table of Contents}

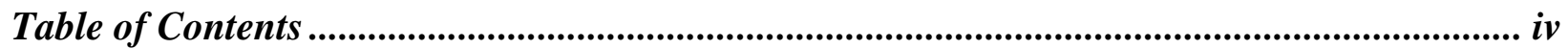

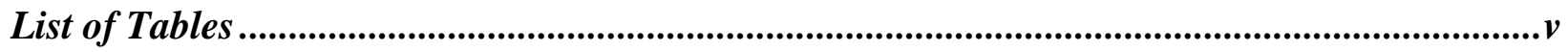

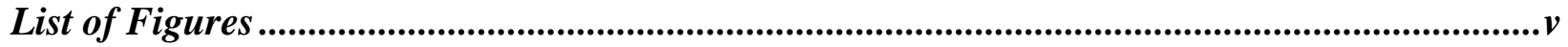

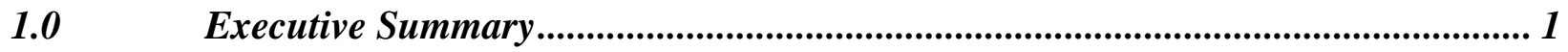

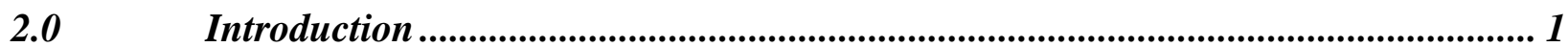

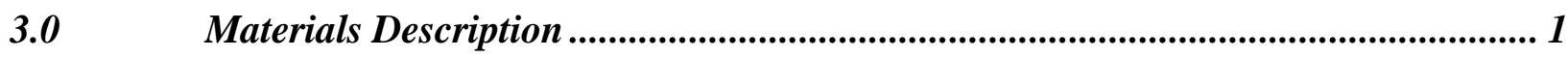

4.0 Calculational Approach and Methodology.......................................................... 5

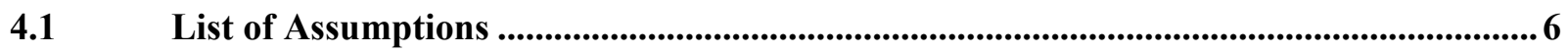

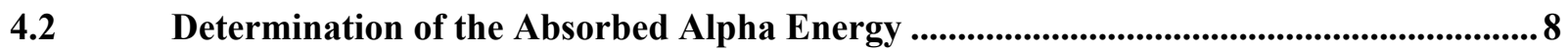

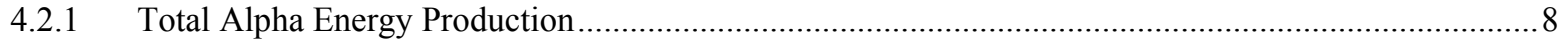

4.2.2 Parametric Evaluation of Fraction of Total Alpha Energy Absorbed by Bottle in Drums \#3031 \& \#3598 ..................................................................................

4.2.3 Final Estimation of Hydrogen Generation in Drums \#3031 \& \#3598 _..............................................11

4.2.4 Hydrogen Production in DOT 6M drum \#20102 ............................................................................. 13

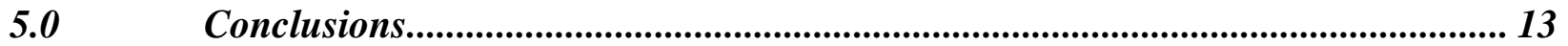

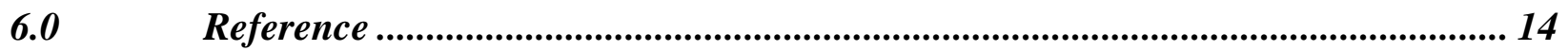




\section{List of Tables}

Table 1 Summary of the Uranium-Fissium Debris Contained in Three DOT 6M 30-gallon Drums ........................5

Table 2 Summary Table of Calculations for Power Density Determination ${ }^{-}$...........................................................8

Table 3 Summary Table of Calculations for Maximum Total Energy Generation due to Alpha Decay of Isotopes in HCL-1 and HCL-2 and 114/133 SAL ....................................................................... 9

Table 4 Summary Table of Hydrogen Generation, Pressure Increase, and Concentration Results ...................... 13

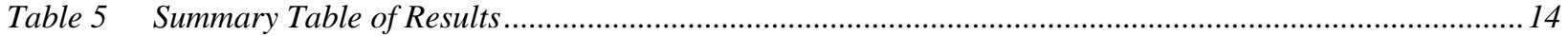

\section{List of Figures}

Figure 1 Photograph of the recovered metallic pieces recovered from ICPP HCL.............................................2

Figure 2 Schematic representation of the packaging configuration for DOT 6M 30-gallon drums \#3031

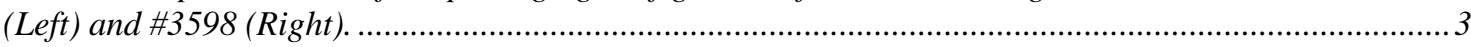

Figure 3 Schematic representation of the packaging configuration for DOT 6M 30-gallon drum \#20102. ..............4

Figure 4 Photograph of the crimp-sealed tin can (114/133 SAL) that is stored in a 2R container within the DOT 6M 30-gallon drum \#20102.

Figure 5 Schematic of the model used to determine fraction of alpha energy deposited in HDPE bottles in drum \#3031, can HCL-1 and \#3598, can HCL-2. ....

Figure 6 Hydrogen production rate as a function of modeled source density for drum \#3031, can HCL-1............11

Figure 7 Hydrogen production rate as a function of modeled source density for drum \#3598, can HCL-2. ...........12 


\subsection{EXECUTIVE SUMMARY}

Three DOT 6M 30-gallon drums are scheduled to be shipped from the Idaho Nuclear Technology Engineering Center (INTEC) at the Idaho National Laboratory (INL) to L-Area at the Savannah River Site (SRS). These three drums contain radioactive materials that resulted from the material recovery effort following a small explosion that had occurred in the Idaho Chemical Processing Plant (ICPP) hot chemistry laboratory (HCL). In support of the shipment and subsequent storage of the three DOT 6M drums, an evaluation of the potential for molecular hydrogen production in the drums has been completed and documented herein. The potential sources of hydrogen evaluated in the current report include radiolytic decomposition of polymeric materials in the DOT 6M drums \#3031 and \#3598 and the radiolytic decomposition of water in drum $\# 20102$. No other potential sources have been identified based upon reported drum contents and packaging configuration. ${ }^{1-2}$

A parametric approach was used to evaluate the maximum quantity of molecular hydrogen that can be expected to evolve in two DOT 6M 30-gallon drums in support of receipt and subsequent interim storage prior to canyon processing. These drums are two of three drums scheduled for shipment from INTEC to SRS as part of the decommissioning effort of the INTEC facility. The three DOT 6M drums will be received at L-Area in SRS and stored for up to 13-years prior to final disposition at HB-Line in 2020. Results of the current analysis do not include parametric analysis of drum \#20102 containing 114/133 SAL (salvage) which contains $\mathrm{UO}_{3}$ powder. This drum has not been identified as containing polymeric materials and a conservative calculation indicates that the maximum gross molecular hydrogen production due to the radiolysis of adsorbed moisture would yield a production rate of $5.1-\mathrm{cm}^{3} / \mathrm{yr}$, driven primarily by the large surface are to volume ratio of the oxide powder. The remaining two drums, \#3031 and \#3598 contain polymer bags and/or bottles that will be subject to radiolytically induced hydrogen gas generation due to decomposition of the polymers. Conservative values for hydrogen gas generation rates and rates of pressure increase within the drums have been determined based upon a number of inputs and assumptions. The results are that hydrogen will be produced at a rate of $1.93-\mathrm{cm}^{3} / \mathrm{yr}$ and $1.50-\mathrm{cm}^{3} / \mathrm{yr}$, respectively for drums \#3031 and \#3598. Projected molecular hydrogen concentrations at 2020 have been calculated to remain below the lower flammability limit of $4 \%$ molecular hydrogen by volume in air.

\subsection{INTRODUCTION}

Three DOT 6M 30-gallon drums are planned to be shipped from the Idaho Nuclear Technology Engineering Center (INTEC) at the Idaho National Laboratory (INL) to L-Area at the Savannah River Site (SRS). These three drums contain radioactive materials that resulted from the material recovery effort following a small explosion that had occurred in the Idaho Chemical Processing Plant (ICPP) hot chemistry laboratory (HCL). The three DOT 6M drums would be received at L-Area in SRS and stored for up to 13-years prior to final disposition at HB-Line by 2020. In support of the shipment and subsequent storage of the three DOT 6M drums, an evaluation of the potential for molecular hydrogen production in the drums due to the radiolytic decomposition of the polymer bottles in drums \#3031 and \#3598 and due to radiolytic decomposition of water reported in drum \#202102 has been completed and documented herein.

\subsection{MATERIALS DESCRIPTION}

Three DOT 6M 30-gallon drums are planned to be shipped from the Idaho Nuclear Technology Engineering Center to the Savannah River Site. The debris in each drum has been carefully characterized by personnel at the ICPP HCL. ${ }^{3}$ Two of the three DOT 6M 30-gallon drums from INTEC, \#3031 and \#3598, contain a variety of materials that are characterized as quarter circles, pins, pellets, foils, wires, chips, turnings, and small filings/specks. The two largest pieces that are roughly shaped as quarter circles with a $5-\mathrm{cm}$ radius and that are two centimeters thick are contained in drum \#3598. They are 
characterized as $4.5 \mathrm{wt} \%$ uranium fissium alloy which are contaminated with ${ }^{239} \mathrm{Pu}(200-400 \mathrm{ppm}) .{ }^{2}$ These two pieces are located in areas 7 and 14 of Figure 1. Figure 2 provides a graphical depiction of loading of the two 30 gallon DOT 6M drums. In drum \#3598, the two quarter circles are each within a low-density polyethylene bag and the two bags within a 500-ml high-density polyethylene (HDPE) bottle. The HDPE bottle is closed with a screw cap and placed within a crimp-sealed tin can, HCL-2, that is placed inside the sealed 2R container within the DOT 6M 30-gallon drum. The can contains 1,190 grams of total uranium of which 617 grams are ${ }^{235} \mathrm{U}$.

Drum \#3031 contains the remaining metallic pieces shown in the photograph of Figure 1. These pieces are counted as 45 pins, 19 pellets, 7 foils, 4 wires, 3 chips, 131 turnings, and 1083 small filings/specks. These pieces are contained within a 500-ml HDPE bottle that is contained in a crimp-sealed tin can, HCL-1 that is sealed in the 2R container within the DOT 6M 30-gallon drum (see Figure 2). All of the pellets and chips and a majority of pins, foils, and small filing/specks are described as uranium fissium alloy low in zirconium. The uranium fissium alloy is $3.5 \mathrm{or} 4.5 \mathrm{wt} \%$ fissium. The remaining material in this can consists of a small number of pins, foils, and small filing/specks that consist of a uranium alloy high in zirconium. Also stored in the can as foils, wires, turning, wire, and small filings/specks is a small quantity (gram amounts) of metal: Inconel, stainless steel (304), thorium, and nickel alloy. The material is contaminated with ${ }^{239} \mathrm{Pu}(200-400 \mathrm{ppm})$. The can, HCL-1, contains 290 grams of total uranium of which 255 grams are ${ }^{235} \mathrm{U}$.

The third DOT 6M 30-gallon drum is labeled \#20102 and contains material described as soil samples. The soil sample material is characterized as $\mathrm{UO}_{3}$ granular powder, a high-grade uranium oxide product obtained from reprocessing fuel and scrap material at INTEC. ${ }^{1}$ The material is comprised of 29 grams of total uranium, of which 26 grams are ${ }^{235} \mathrm{U}$. In addition, this drum is reported to contain 0.45 -g of water due to the hygroscopic nature of the uranium-oxide. This material is contained within the crimp sealed tin can 114/133 SAL shown in Figure 4 that is within the 2R inside the DOT 6M 30-gallon drum as depicted in Figure 3.

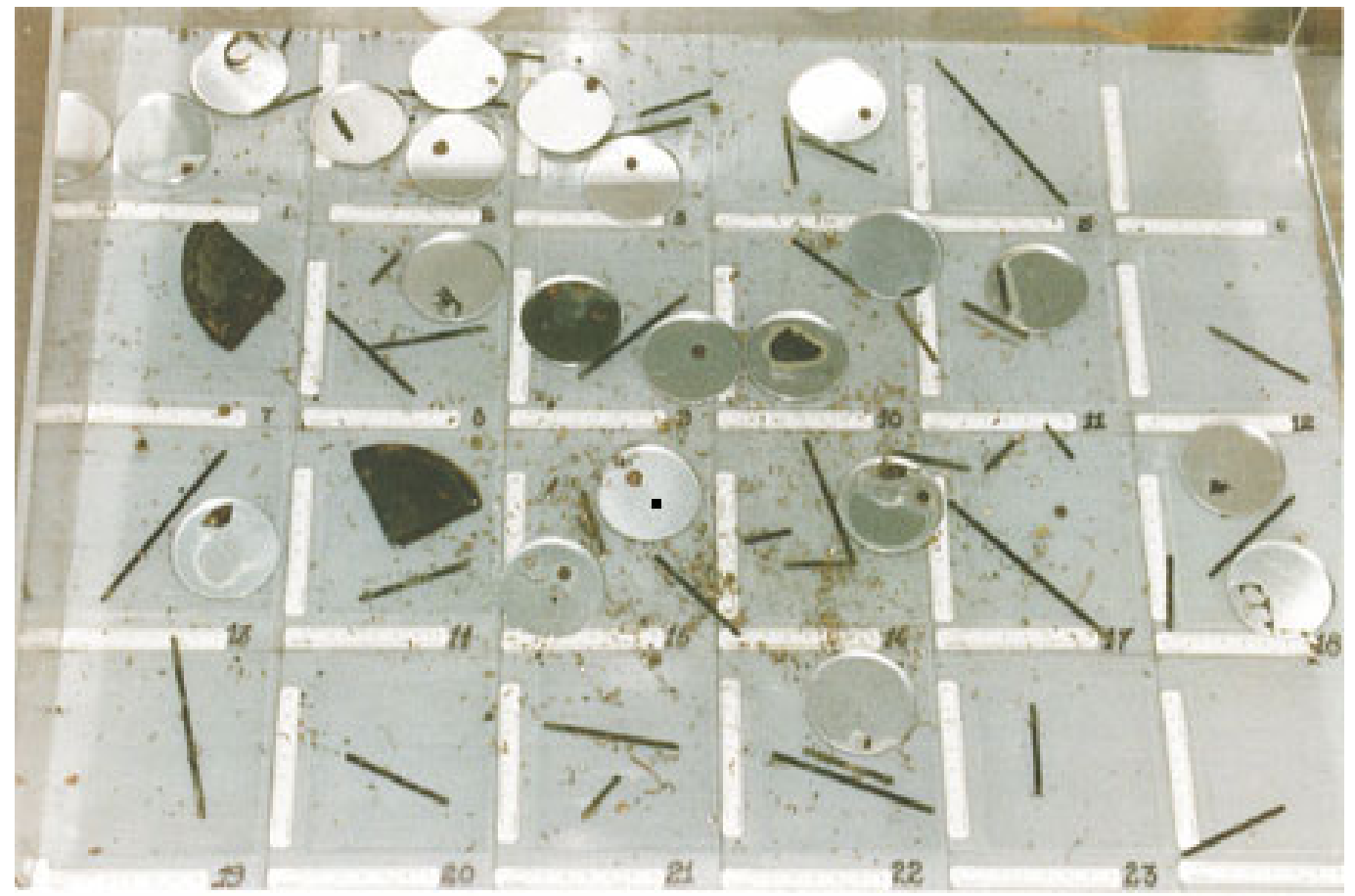

Figure 1 Photograph of the recovered metallic pieces recovered from ICPP HCL. 

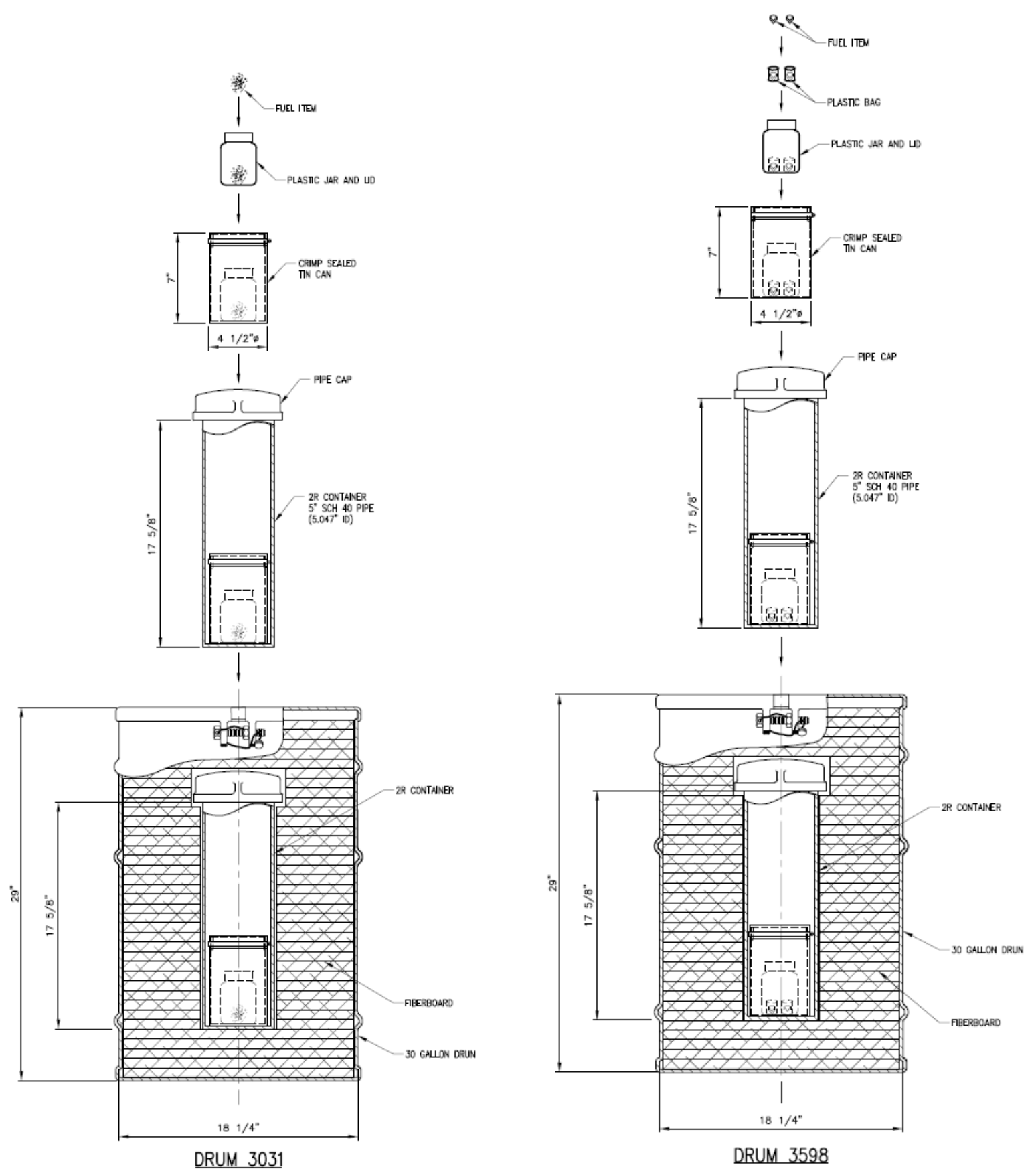

Figure 2 Schematic representation of the packaging configuration for DOT 6M 30-gallon drums \#3031 (Left) and \#3598 (Right). 


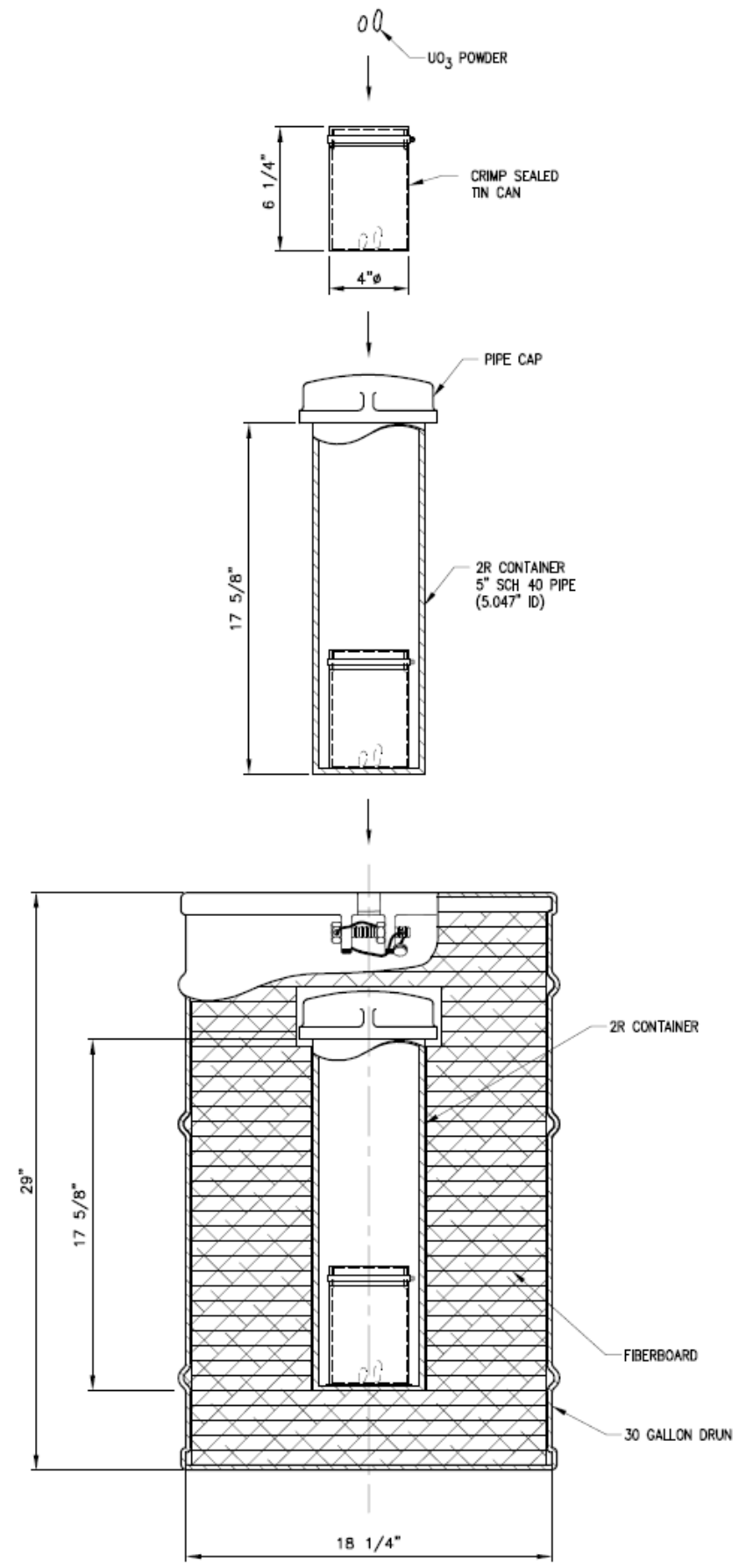

DRUM 20102

Figure 3 Schematic representation of the packaging configuration for DOT 6M 30-gallon drum \#20102. 


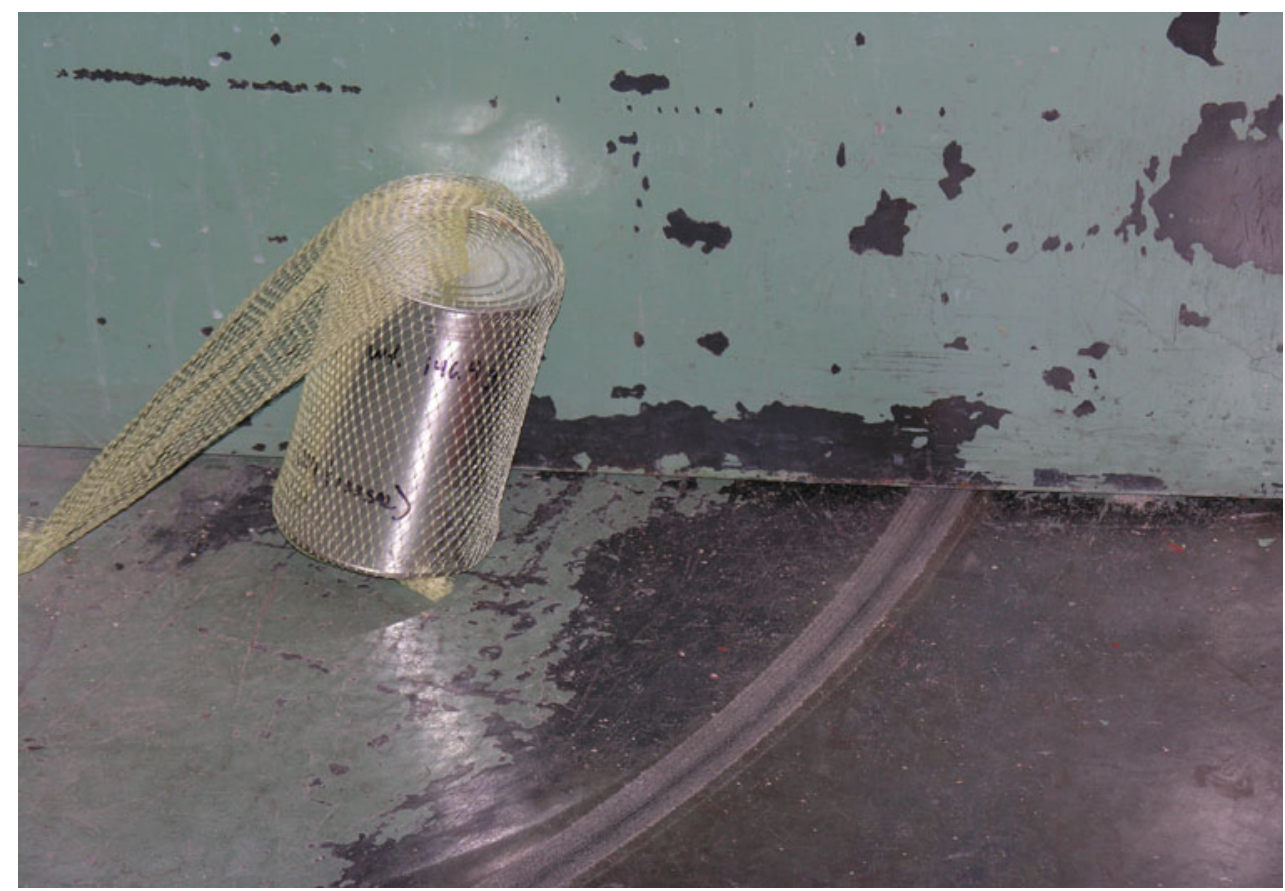

Figure 4 Photograph of the crimp-sealed tin can (114/133 SAL) that is stored in a $2 \mathrm{R}$ container within the DOT 6M 30-gallon drum \#20102.

Table 1 Summary of the Uranium-Fissium Debris Contained in Three DOT 6M 30-gallon Drums

\begin{tabular}{|c|c|c|c|c|}
\hline Can/Drum & Description & Form & Total U (g) & Total Pu (g) \\
\hline $\begin{array}{l}\text { HCL-1 } \\
\# 3031\end{array}$ & Uranium-Fissium (3.5-4.5\%) & $\begin{array}{l}45 \text { pins, } \\
19 \text { pellets, } \\
7 \text { foils, } \\
4 \text { wires, } \\
3 \text { chips, } \\
131 \text { turnings, } \\
1083 \\
\text { filings/specks }\end{array}$ & 290 & 0.12 \\
\hline $\begin{array}{l}\text { HCL-2 } \\
\# 3598\end{array}$ & Uranium-Fissium (3.5-4.5\%) & $\begin{array}{l}2 \text { large quarter } \\
\text { round chunks }\end{array}$ & 1,190 & 0.48 \\
\hline $\begin{array}{l}\text { 114/133 SAL } \\
\# 20102\end{array}$ & High-Grade $\mathrm{UO}_{3}$ Powder & $\begin{array}{l}\mathrm{UO}_{3} \text { Granular } \\
\text { Powder }\end{array}$ & 29 & 0 \\
\hline
\end{tabular}

\subsection{CALCULATIONAL APPROACH AND METHODOLOGY}

The potential sources of hydrogen evaluated in the current report include radiolytic decomposition of polymeric materials in the DOT 6M drums \#3031 and \#3598 and the radiolytic decomposition of water in drum \#20102. No other potential sources have been identified based upon reported drum contents and packaging configuration. ${ }^{1-2}$ 
Ionizing radiation causes radiolytic decomposition of polymers. The decomposition of polymers lead to the production of molecular hydrogen. The general approach used to develop an estimate of the potential for molecular hydrogen generation due to alpha radiolysis of polymers follows the approached used by Croft Associates for the SAFKEG package ${ }^{4}$. The rate of production of $\mathrm{H}_{2}$ from decomposition of polymeric material in units of $\mathrm{cm}^{3} / \mathrm{sec}\left(\mathrm{V}_{\mathrm{g}}\right)$ can be generally expressed as:

$V_{g}=\left(D \times G \times k \times v / A_{n}\right)$

where: $\quad \mathrm{D}=$ alpha energy absorbed in the polymer (Watts),

$\mathrm{G}=$ hydrogen gas generation constant (Molecules/MeV)

$\mathrm{k}=$ conversion factor $(6.24 \mathrm{e} 12 \mathrm{Mev} / \mathrm{J})$,

$\mathrm{v}=$ volume of 1 mole of gas at STP $\left(2.24 \mathrm{e}^{\mathrm{cm}} \mathrm{cm}^{3}\right)$, and

$\mathrm{A}_{\mathrm{n}}=$ Avogadro's number (6.022e 23 molecules).

For the current work, the alpha energy absorbed in the polymer, D, and the value of the hydrogen gas generation constant, $\mathrm{G}$, are the two unknowns in Eq. 1. For the determination of $\mathrm{D}$, it is necessary to determine the range of alpha particles in the various materials. The energy and material dependant range of an alpha particle in $\mathrm{cm}(\mathrm{R})$ is determined by the equation: ${ }^{5-6}$

$R=2.3 \times 10^{-4}\left(\frac{\sqrt{M}}{\rho}\right)\left(1.24 E_{\alpha}-2.62\right)$

where: $\quad \mathrm{M}=$ molecular weight of the medium (AMU),

$\rho=$ density of the medium $\left(\mathrm{g} / \mathrm{cm}^{3}\right)$, and

$\mathrm{E}_{\alpha}=$ average alpha energy $(\mathrm{MeV})$.

For the current work, the molecular weight and density of the medium and the average alpha energy are the three unknowns in Eq. 2. Having determined the volume of molecular hydrogen produced using Eq. 1, it is then possible to determine the pressure rise within the package as a function of time $\left(\mathrm{P}_{\mathrm{r}}(\mathrm{t})\right)$ by the equation: ${ }^{4}$

$$
P_{r}(t)=\left(P_{\mathrm{a}} \times V_{\mathrm{g}} \times t / V_{c}\right)
$$

where: $\quad \mathrm{P}_{\mathrm{a}}=$ ambient pressure $(1.0 \mathrm{bar} \mathrm{abs})$,

$\mathrm{t}=$ time (secs), and

$\mathrm{V}_{\mathrm{c}}=$ free volume of container $\left(\mathrm{cm}^{3}\right)$.

For the current work, the time, $t$, and free volume of the container, $\mathrm{V}_{\mathrm{c}}$ are the two unknowns in Eq. 3 .

The next section of the report addresses the assumptions, methodology, and calculations used to develop a conservative estimate of the expected molecular hydrogen production due to the contents of the drums as described in the previous section.

\subsection{List of Assumptions}

1. The value of the hydrogen gas generation constant (G-value) is assumed equal 3.5 molecules $/ 100 \mathrm{eV}$ or $3.5 \times 10^{4}$ molecules $/ \mathrm{MeV}$. This value of $\mathrm{G}$ is taken from Reference 7 as the highest reported production rate for all polymers due to radiolytic decomposition by 
incident alpha radiation. This assumption is conservative because no credit is taken for the dose dependent nature of radiation damage in the polymer. Increasing the dose absorbed by a polymer will decrease the effective G-value for hydrogen production due to the depletion of the matrix in the vicinity of the alpha-emitting radioactive source particle. Dose dependent $G$ values are reported as less than $1 / 5$ th the value assumed in the current analysis. ${ }^{8}$

2. The value used for the molecular weight of the material in the HDPE bottles is $242-\mathrm{g} / \mathrm{mole}$. This number is consistent with that of plutonium. This number bounds the actual effective molecular weight of the contents of the drums, since the contents include fissium elements whose weights are generally less than 100 . This assumption is conservative as alpha range increases as the square-root of the molecular weight (see Eq. 2).

3. The bottle is modeled as a right-circular cylinder with a 4-cm radius and a height of 14.2-cm. This assumption is conservative as the surface area of the modeled $\sim 700-\mathrm{ml}$ bottle is greater than that of the expected 500-ml bottle actually used.

4. It is assumed that the materials in drums \#3031 and \#3598 are essentially dry. Unlike the materials in drum \#20102, this material is not hygroscopic in nature and water content in these drums would be mostly limited to humidity in the facility. Radiolysis of bulk water in these two drums will not provide significant molecular hydrogen production relative to the production estimated for the production due to polymeric radiolytic decomposition. The short range of the alpha particles, the conservatism introduced by Assumption 1, and the G-value of $1.7 \times 10^{4}$ molecules $/ \mathrm{MeV}^{9}$ for $\mathrm{H}_{2}$ generation from alpha radiolysis of water support this assumption.

5. The average alpha energy used in Eq. 2 is assumed equal to $5.25-\mathrm{MeV}$. This value bounds the alpha particles from all isotopes identified as being in the drums per the Appendix A and supporting documentation.

6. It is assumed that the free volume of the $2 \mathrm{R}$ containers and the crimp-sealed tin cans in the DOT $6 \mathrm{M} 30$-gallon drums is equal to $90 \%$ of their physical volume. This assumption is conservative as the contents of the tin cans are expected to occupy less than $7 \%$ of the tin can and less than $3 \%$ of the $2 \mathrm{R}$ containers. ${ }^{3}$ Increasing the free volume of the containers will further decrease the estimated pressure increase with time by Eq. 3 .

7. It is assumed that only $50 \%$ of the alpha particles that are produced within range of the polymer surface contribute to the energy absorbed by the polymer. This assumption accounts for the fact that an isotropic source would generate $50 \%$ of its particles in a direction that takes the particle away from the polymer surface.

8. It is assumed that the methodology employed in the current parametric evaluation of the HDPE bottles whereby the source material is assumed to completely cover the inner surface of bottle with a homogeneous layer of variable density and related alpha particle range dictated by the layer thickness and the total source material available is sound and bounding.

9. It is assumed that the bags are not present in HCL-2. This is conservative because the surface area of source material in contact with the polymer bottle is significantly increased by ignoring the plastic bags based upon the current model.

10. It is assumed that there is no polymeric material in DOT 6M 30-gallon drum \#20102. There is no indication of the presence of any polymeric bags or bottles as evidenced by the loading schematic shown in Figure 3.

11. It is assumed that the bottle is not an effective barrier to hydrogen migration for the pressure rise calculations. This is reasonable due to the high permeability of molecular hydrogen through polyethylene. ${ }^{10}$ The crimp-sealed tin can is also ignored for pressure rise calculations for the $2 \mathrm{R}$.

12. The start time for hydrogen accumulation calculations for drums \#3031 and 3598 is assumed equal to 1992. This is a conservative assumption based upon the date at which the HCL crimp-sealed tin cans were loaded. ${ }^{3}$ 
13. The start time for the hydrogen accumulation calculations for drum \#20102 is assumed equal to $2006 .^{11}$

14. The 0.45 -g of water reported for drum $\# 20102^{1}$ is assumed homogeneously mixed with alphaproducing uranium within the drum. That is to say that no credit is taken for the shielding effects of the $\mathrm{UO}_{3}$ particles themselves in the current calculation. In addition, no credit is taken for recombination or reverse reactions by which molecular hydrogen is consumed to regenerate water molecules. This is a conservative assumption.

\subsection{Determination of the Absorbed Alpha Energy}

\subsubsection{Total Alpha Energy Production}

The total production of alpha particles generated in each of the crimp-sealed tin containers is completely dependent upon contents of the tin can. References 3-1 provide a list of the radioactive isotopes and quantities contained in each of the three DOT 6M 30-gallon drums. Tables $2 \& 3$ provide the alpha decay energy and isotopic content by weight for the three drums. Table 2 shows the calculation to determine the power density for each of the isotopes included in the $6 \mathrm{M}$ 's. The power density is calculated as the product of the average alpha energy per alpha particle as obtained from the ENDF-VI decay library and the activity density of isotope as obtained from 10CFR71. ${ }^{12}$ The total alpha energy generation due to radioactive decay can then be calculated and results are shown in Table 3, where the energy generation by isotope is the product of the power density and the total grams as obtained from the Appendix A documents. $^{1-2}$

Table 2 Summary Table of Calculations for Power Density Determination ${ }^{12-13}$

\begin{tabular}{|l|c|c|c|c|c|}
\hline Isotope & $\begin{array}{c}\mathbf{E}_{\boldsymbol{a}} \\
(\mathbf{M e V})\end{array}$ & $\begin{array}{c}\mathbf{E}_{\boldsymbol{\alpha}} \\
\mathbf{J} / \boldsymbol{\alpha}\end{array}$ & $\begin{array}{c}\text { Activity } \\
\text { Density } \\
(\mathbf{C i} / \mathbf{g})\end{array}$ & $\begin{array}{c}\text { Activity } \\
\text { Density } \\
(\mathbf{B q} / \mathbf{g})\end{array}$ & $\begin{array}{c}\text { Power Density } \\
\text { (Watts/g) }\end{array}$ \\
\hline${ }^{234} \mathbf{U}$ & 4.8419 & $7.76 \times 10^{-13}$ & $6.20 \times 10^{-3}$ & $2.29 \times 10^{8}$ & $1.78 \times 10^{-4}$ \\
\hline${ }^{235} \mathbf{U}$ & 4.4709 & $7.16 \times 10^{-13}$ & $2.20 \times 10^{-6}$ & $8.14 \times 10^{4}$ & $5.83 \times 10^{-8}$ \\
\hline${ }^{236} \mathbf{U}$ & 4.5563 & $7.30 \times 10^{-13}$ & $6.50 \times 10^{-5}$ & $2.41 \times 10^{6}$ & $1.76 \times 10^{-6}$ \\
\hline${ }^{238} \mathbf{U}$ & 4.2610 & $6.83 \times 10^{-13}$ & $3.40 \times 10^{-7}$ & $1.26 \times 10^{4}$ & $8.59 \times 10^{-9}$ \\
\hline${ }^{239} \mathbf{P u}$ & 5.2375 & $8.39 \times 10^{-13}$ & $6.20 \times 10^{-2}$ & $2.29 \times 10^{9}$ & $1.92 \times 10^{-3}$ \\
\hline${ }^{240} \mathbf{P u}$ & 5.2429 & $8.40 \times 10^{-13}$ & $2.30 \times 10^{-1}$ & $8.51 \times 10^{9}$ & $7.15 \times 10^{-3}$ \\
\hline
\end{tabular}


Table 3 Summary Table of Calculations for Maximum Total Energy Generation due to Alpha Decay of Isotopes in HCL-1 and HCL-2 and 114/133 SAL

\begin{tabular}{|c|c|c|c|c|c|c|c|}
\hline \multirow[b]{2}{*}{ Isotope } & \multicolumn{3}{|c|}{ Composition by Can/Drum ${ }^{\dagger}$} & \multirow[b]{2}{*}{$\begin{array}{c}\text { Power } \\
\text { Density } \\
\text { (Watts/g) }\end{array}$} & \multicolumn{3}{|c|}{ Energy Generation by Can/Drum } \\
\hline & $\begin{array}{c}\text { HCL-1 } \\
\# 3031 \\
\text { (grams) }\end{array}$ & $\begin{array}{c}\text { HCL-2 } \\
\# 3598 \\
\text { (grams) }\end{array}$ & $\begin{array}{c}114 / 133 \mathrm{SAL} \\
\# 20102 \\
\text { (grams) }\end{array}$ & & $\begin{array}{c}\text { HCL-1 } \\
\# 3031 \\
\text { (Watts) }\end{array}$ & $\begin{array}{c}\text { HCL-2 } \\
\# 3598 \\
\text { (Watts) }\end{array}$ & $\begin{array}{l}\text { 114/133 SAL } \\
\text { \#20102 } \\
\text { (Watts) }\end{array}$ \\
\hline${ }^{234} \mathbf{U}$ & 2.17 & 6.25 & 0.22 & $1.78 \times 10^{-4}$ & $3.86 \mathrm{E}-04$ & $1.11 \mathrm{E}-03$ & $3.91 \mathrm{E}-05$ \\
\hline${ }^{235} \mathbf{U}$ & 255.00 & 617.00 & 26.00 & $5.83 \times 10^{-8}$ & $1.49 \mathrm{E}-05$ & $3.60 \mathrm{E}-05$ & $1.52 \mathrm{E}-06$ \\
\hline${ }^{236} \mathbf{U}$ & 0.93 & 1.09 & 0.1 & $1.76 \times 10^{-6}$ & $1.63 \mathrm{E}-06$ & $1.91 \mathrm{E}-06$ & $1.76 \mathrm{E}-07$ \\
\hline${ }^{238} \mathbf{U}$ & 31.90 & 565.66 & 2.68 & $8.59 \times 10^{-9}$ & $2.74 \mathrm{E}-07$ & $4.86 \mathrm{E}-06$ & $2.30 \mathrm{E}-08$ \\
\hline Total U & 290.00 & 1190.00 & 29.00 & & $4.03 \mathrm{E}-04$ & $1.15 \mathrm{E}-03$ & 4.09E-05 \\
\hline${ }^{239} \mathrm{Pu}$ & 0.11 & 0.46 & - & $1.92 \times 10^{-3}$ & $2.12 \mathrm{E}-04$ & $8.85 \mathrm{E}-04$ & - \\
\hline${ }^{240} \mathrm{Pu}$ & 0.01 & 0.02 & - & $7.15 \times 10^{-3}$ & $7.15 \mathrm{E}-05$ & $1.43 \mathrm{E}-04$ & - \\
\hline Total Pu & 0.12 & 0.48 & - & & $2.83 \mathrm{E}-04$ & $1.03 \mathrm{E}-03$ & - \\
\hline \multicolumn{5}{|c|}{ Aggregate Total Energy Generation } & $6.86 \mathrm{E}-04$ & 2.18E-03 & 4.09E-05 \\
\hline
\end{tabular}

$\dagger$ Taken from Reference 3.

From Tables $2 \& 3$, it is determined that the total alpha energy production in HCL-1 and HCL-2 is $6.86 \times 10^{-4}$-Watts and $2.18 \times 10^{-3}$-Watts, respectively. The alpha energy generation rate for drum \#20102 is used to determine the maximum molecular hydrogen generation rates in this drum due to the radiolytic decomposition of the water contents of this drum as prescribed in Section 4.2.4. This drum is not considered in the parametric calculations used to determine the maximum molecular hydrogen generation rate due to the radiolytic decomposition of the polymers in the two remaining drums. The approach to the determination of the fraction of alpha energy that contributes to the radiolytic decomposition of polymeric material in the two remaining drums, \#3031 and \#3598 is described in Section 4.2.2.

\subsubsection{Parametric Evaluation of Fraction of Total Alpha Energy Absorbed by Bottle in Drums \#3031 \& \#3598}

A parametric approach was used in the evaluation to determine the maximum fraction of the total alpha particle energy that may be absorbed by the HDPE bottle. Figure 5 provides a schematic of the approach whereby the source material is assumed to occupy a homogeneous volume that is in contact with the inner surface of the HDPE bottle. The variables are the radius and height of the void region in the model (see Figure 5). As the radius and height vary as an increasing fraction of the bottle dimensions, the density of the source region is calculated as:

$$
\rho_{\text {source }}=\frac{290.12 \text { or } 1190.48}{V_{\text {bottle }}-V_{\text {void }}}
$$

where 290.12 or 1190.48 are used to represent the total source mass in grams in for drum \#3031, can HCL-1 and drum \#3598, can HCL-2, respectively, $V_{\text {bottle }}$ is the total bottle volume of 714- $\mathrm{cm}^{3}$. For the purpose of this calculation the value of $\mathrm{V}_{\text {void }}$ can vary from $\sim 0-\mathrm{cm}^{3}$ to $\sim 714-\mathrm{cm}^{3}$. As the void region increases in volume, the source region volume decreases and the density of the layer on the bottle increases as described in Eq. 4. The values of source region density calculated from Eq. 4 are used in Eq. 2 to determine the alpha range in the homogeneous source material region. The width of the contributing source region is equal to the alpha particle range. The calculated alpha particle range is then used to describe the contributing and noncontributing components of the source regions. The contributing mixture in Figure 5 is the homogeneous source region volume that is within the alpha range of the inner surface of the modeled cylindrical bottle. The total source region volume is the difference between the 
bottle volume and the void region volume. The ratio of the contributing mixture volume divided by the total source region volume provides a conservative estimate of the fraction of alpha particle energy that is created within the range of an alpha particle of the surface of the HDPE bottle. This fraction is then applied to the total alpha particle energy in the last row of Table 3 to determine the energy generated by alpha decay in the contributing mixture volume. This total energy is then divided by a factor of 2 to account for the isotropic nature of the source material to result in the total energy that is absorbed in the polymer to generate molecular hydrogen (that is D in Eq. 1).

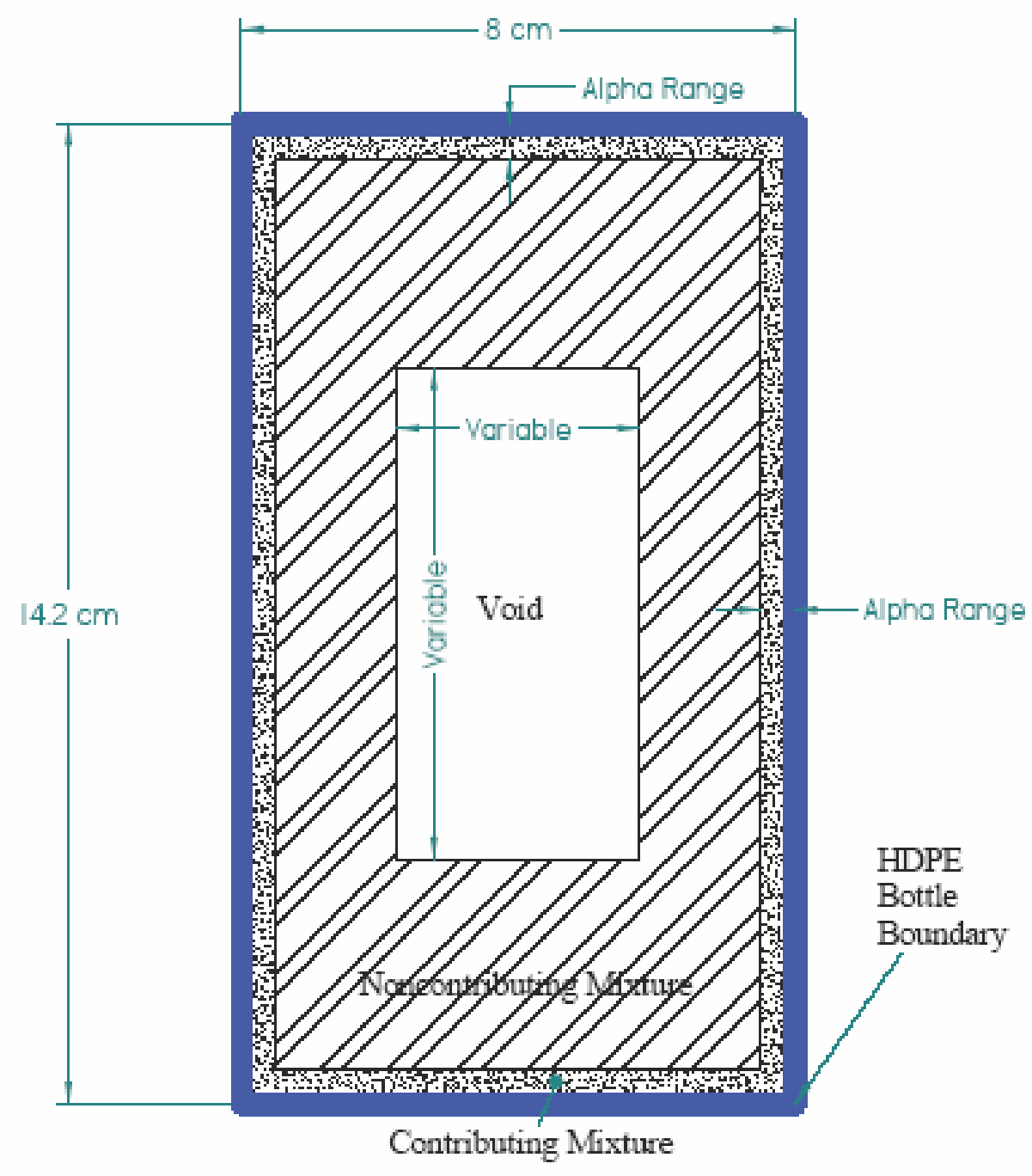

Figure 5 Schematic of the model used to determine fraction of alpha energy deposited in HDPE bottles in drum \#3031, can HCL-1 and \#3598, can HCL-2. 


\subsubsection{Final Estimation of Hydrogen Generation in Drums \#3031 \& \#3598}

The parametric approach as described in the previous section results in the consideration of hypothetical scenarios by which the modeled densities range from $0.4-\mathrm{g} / \mathrm{cm}^{3}$ to more than $5000-\mathrm{g} / \mathrm{cm}^{3}$. While these values are unrealistic, irregular material sizes and shapes and uncertainty in material composition and effective packing efficiency have instigated the current parametric methodology that evaluates all theoretically possible values of material and effective packing density. Although such densities are considered in order to bound analytically all possible material densities, it is expected that the actual material density would not achieve a density larger than that of uranium metal or about $18.9-\mathrm{g} / \mathrm{cm}^{3}$. The plots of Figures $6 \&$ 7show that the hydrogen production rates for drum \#3031, can HCL-1 and drum \#3598, can HCL-2 change only slightly as material density is increased above $18.9-\mathrm{g} / \mathrm{cm}^{3}$. From this figure it is apparent that the maximum production rates are achieved as the material density is increased. This indicates that the shielding effect gained by the increased density of the source material, and decreased alpha particle range, as it is moved closer to the inner surface of the HDPE bottle effectively negates closer proximity of the alpha emitting material to the inner surface of the HDPE bottle.

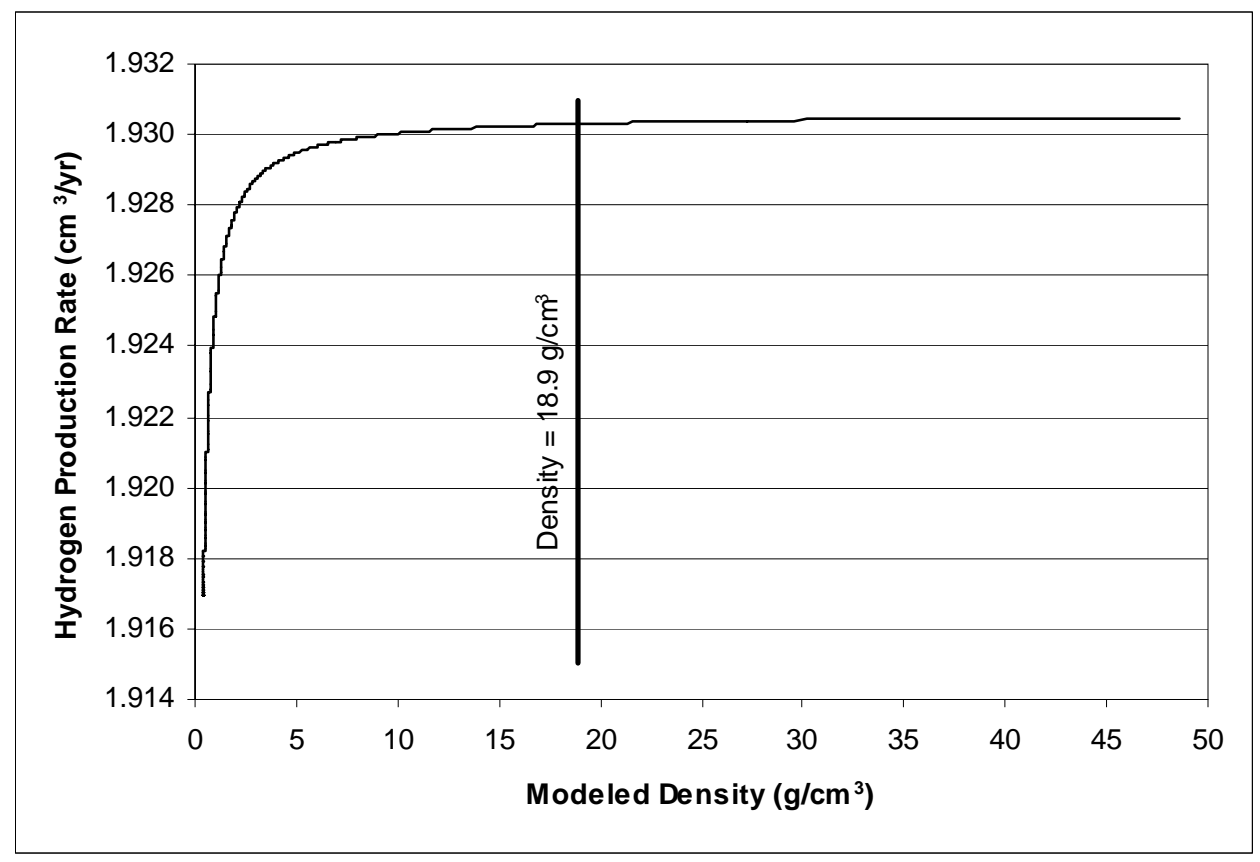

Figure 6 Hydrogen production rate as a function of modeled source density for drum \#3031, can HCL-1. 


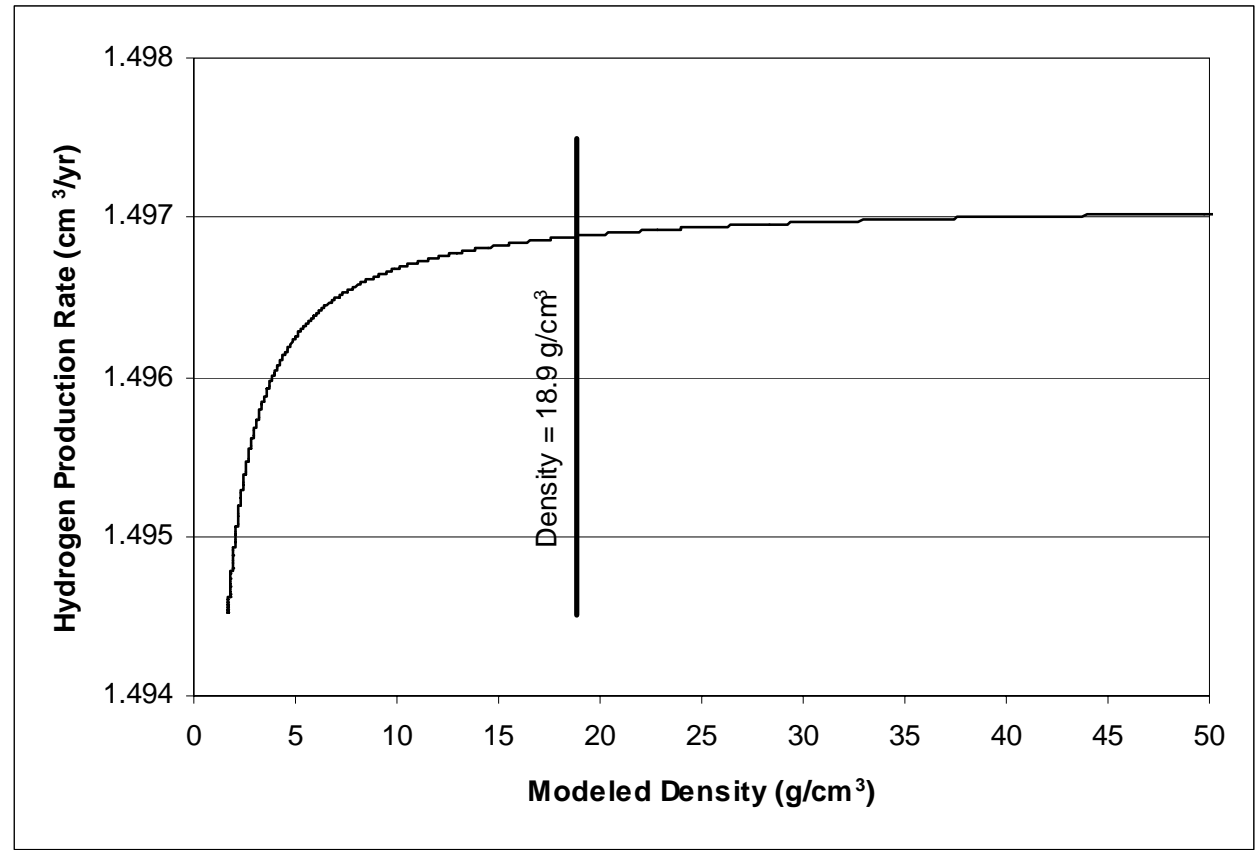

Figure 7 Hydrogen production rate as a function of modeled source density for drum \#3598, can HCL-2.

The following calculation provides an illustration of the use of the current methodology in the determination of hydrogen production rate in the DOT 6M 30-gallon drums assuming a density of $18.9-\mathrm{g} / \mathrm{cm}^{3}$. Based upon assumptions 2 and 5 in Section 4.1 and Eq. 2, the range of a $5.25 \mathrm{MeV}$ alpha particle in source material contained within the HDPE bottle would be calculated as $7.36-\mu \mathrm{m}$. The assumed density of $18.9-\mathrm{g} / \mathrm{cm}^{3}$ requires that the total mixture volume (that is the sum of the contributing and noncontributing volumes in Figure 5) equal $15.35-\mathrm{cm}^{3}$ and $62.99-\mathrm{cm}^{3}$, for drum \#3031, can HCL-1 and drum \#3598, can HCL-2, respectively. These values are determined as the material mass provided in Tables $1 \& 3$ divided by $18.9-\mathrm{g} / \mathrm{cm}^{3}$. The contributing volume illustrated in Figure 5 is determined with the aid of assumption 3 for HDPE dimensions and the calculated alpha particle range of $7.36-\mu \mathrm{m}$. Based upon the dimensions provided in assumption 3, that is a 4-cm radius and a height of $14.2-\mathrm{cm}$, the total volume of the bottle is $713.76-\mathrm{cm}^{3}$. The material of density $18.9-\mathrm{g} / \mathrm{cm}^{3}$ would occupy a space that is outside the cylinder whose radius is $(4-0.000736)-\mathrm{cm}$ and whose height is $(14.2-2(0.000736))-\mathrm{cm}$. The volume of this bounding cylinder is determined to be $713.43-\mathrm{cm}^{3}$. The difference of the two volumes is the contributing volume of Figure 5 and is calculated to be $0.33-\mathrm{cm}^{3}$. A simple ratio of $1 / 2$ of the contributing volume to the total mixture volume determines the fraction of generated alpha particles that are assumed to deposit their energy in the HDPE. By this method, the value of D in Eq. 1 is calculated to be equal to $7.53 \times 10^{-6}$-watts and $5.84 \times 10^{-6}$-watts, respectively for HCL-1 and HCL-2. Eq. 1 then yields $6.12 \times 10^{-8}-\mathrm{cm}^{3} / \mathrm{sec}$ or $1.93-\mathrm{cm}^{3} / \mathrm{yr}$ for HCL-1 and $4.74 \times 10^{-8}-\mathrm{cm}^{3} / \mathrm{sec}$ or $1.50-\mathrm{cm}^{3} / \mathrm{yr}$ for HCL-2.

Based upon the calculated hydrogen production rates at an assumed source material density of $18.9-\mathrm{g} / \mathrm{cm}^{3}$, it is calculated that the molecular hydrogen production within HCL-1 will have generated $54-\mathrm{cm}^{3}$ of hydrogen in the 28-year period starting in 1992. This is equivalent to approximately 0.033-bar within the crimp sealed tin can and approximately 0.010 -bar in the $2 \mathrm{R}$ within drum \#3031. In the same time period, the production of molecular hydrogen in HCL-2 will have generated $42-\mathrm{cm}^{3}$ of hydrogen. This is equivalent to approximately 0.026 -bar within the crimp sealed tin can and approximately 0.008 -bar in the $2 \mathrm{R}$ within drum \#3598. Table 4 provides a summary table of these calculations and results. 


\subsubsection{Hydrogen Production in DOT 6M drum \#20102}

The $\mathrm{UO}_{3}$ material in DOT 6M 30-gallon drum \#20102 is reported to contain adsorbed water in the amount of 0.45 -g. This water is conservatively assumed homogeneously mixed with alpha-producing uranium within the drum. That is to say that no credit is taken for the shielding effects of the $\mathrm{UO}_{3}$ particles themselves in the current calculation. Based upon this assumption, the total energy deposition rate of $4.09 \times 10^{-5}$-Watts is absorbed by the water within the drum. Applying this rate as D in Eq. 1 yields a volumetric hydrogen production rate of $1.61 \times 10^{-7}-\mathrm{cm}^{3} / \mathrm{sec}$ or $5.09-\mathrm{cm}^{3} / \mathrm{yr}$ for drum \#20102. This production rate would result in a total hydrogen concentration of $4.0 \%$ by volume in the crimp-sealed can at 2019 and a hydrogen concentration of $1.4 \%$ by volume in the $2 \mathrm{R}$ at 2020 . The molecular hydrogen concentration within the crimp-sealed can remains below the lower flammability limit for hydrogen in air until 2019.

Table 4 Summary Table of Hydrogen Generation, Pressure Increase, and Concentration Results

\begin{tabular}{|c|c|c|c|}
\hline & $\begin{array}{l}\text { HCL-1 } \\
\# 3031\end{array}$ & $\begin{array}{l}\text { HCL-2 } \\
\# 3598\end{array}$ & $\begin{array}{c}\text { 114/133 SAL } \\
\# 20102\end{array}$ \\
\hline $\mathrm{H}_{2}$ Production Rate $\left(\mathrm{cm}^{3} / \mathrm{yr}\right)$ & 1.93 & 1.50 & 5.09 \\
\hline Pressure Increase in Can (bar/yr) & $1.18 \mathrm{E}-03$ & $9.12 \mathrm{E}-04$ & $3.10 \mathrm{E}-03$ \\
\hline Pressure Increase in 2R (bar/yr) & $3.71 \mathrm{E}-04$ & $2.88 \mathrm{E}-04$ & $9.79 \mathrm{E}-04$ \\
\hline $\mathrm{H}_{2}$ Concentration in Can (\% vol) & $3.3^{\dagger}$ & $2.6^{\dagger}$ & $4.0^{+}$ \\
\hline $\mathrm{H}_{2}$ Concentration in $2 \mathrm{R}(\% \mathrm{vol})$ & $1.0^{\dagger}$ & $0.8^{\dagger}$ & $1.4^{\dagger}$ \\
\hline
\end{tabular}

${ }^{\dagger}$ Concentration estimated at 2020 .

$\$$ Concentration estimated at 2019 .

\subsection{CONCLUSIONS}

Three DOT 6m 30-gallon drums will be received in L-Area at SRS and stored for up to 13-years prior to final disposition at HB-Line by 2019/2020. These drums are scheduled for shipment from INTEC to SRS as part of the decommissioning effort of the INTEC facility. Bounding values for hydrogen gas generation rates, rates of pressure increase within the drums, and projected molecular hydrogen concentrations at 2019/2020 have been determined for all three drums based upon the assumptions listed in Section 4.1. Two of these drums, \#3031 and \#3598 contain polymeric bags and/or bottles that will be subject to radiolysis induced hydrogen gas generation. The maximum quantity of molecular hydrogen that can be expected to evolve in two DOT 6M 30-gallon drums in support of receipt and subsequent interim storage prior to canyon processing has been estimated based on the alpha radiolysis of polymers. An upper bound estimate for alpha energy available for radiolysis of the polymeric materials was determined from the volume fraction occupied by material in the bottle packed within an alpha range of the inner surface of the HDPE bottles. A conservative estimation of the hydrogen generation in DOT 6M drum \#20102, can 114/133 SAL that contains $\mathrm{UO}_{3}$ powder due to the radiolytic decomposition of water has also been completed. The results are summarized in Table 5. 
Table 5 Summary Table of Results

\begin{tabular}{|l|c|c|c|}
\hline & $\begin{array}{c}\text { HCL-1 } \\
\mathbf{\# 3 0 3 1}\end{array}$ & $\begin{array}{c}\text { HCL-2 } \\
\mathbf{\# 3 5 9 8}\end{array}$ & $\begin{array}{c}\mathbf{1 1 4} / \mathbf{1 3 3} \text { SAL } \\
\mathbf{\# 2 0 1 0 2}\end{array}$ \\
\hline $\mathbf{H}_{\mathbf{2}}$ Production Rate $\left(\mathbf{c m}^{\mathbf{3}} / \mathbf{y r}\right)$ & 1.93 & 1.50 & 5.09 \\
\hline Pressure Increase in Can (bar/yr) & $1.18 \mathrm{E}-03$ & $9.12 \mathrm{E}-04$ & $3.10 \mathrm{E}-03$ \\
\hline Pressure Increase in 2R (bar/yr) & $3.71 \mathrm{E}-04$ & $2.88 \mathrm{E}-04$ & $9.79 \mathrm{E}-04$ \\
\hline $\mathbf{H}_{\mathbf{2}}$ Concentration in Can (\% vol) & $3.3^{\dagger}$ & $2.6^{\dagger}$ & $4.0^{\dagger}$ \\
\hline $\mathbf{H}_{\mathbf{2}}$ Concentration in 2R (\% vol) & $1.0^{\dagger}$ & $0.8^{\dagger}$ & $1.4^{\dagger}$ \\
\hline
\end{tabular}

${ }^{\dagger}$ Concentration estimated at 2020 .

$\$$ Concentration estimated at 2019 .

\subsection{REFERENCE}

1 “Appendix A: Idaho Cleanup Project, Nuclear Materials Completion,” Carol Nichols, DOESRAAD06-075.1, Draft Document (December 21, 2006).

2 “Appendix A: Idaho Cleanup Project, Nuclear Materials Completion,” Carol Nichols, DOESRAAD06-075, Draft Document (December 21, 2006).

3 DOE/ID-10368, “Uranium/Nitric Acid Processing Explosion at Idaho Chemical Processing Plant: Following-up Investigation Report” (September 1992).

4 R.A. Vaughn, Calculation Sheet, CS 2001/22, Issue C, Project No Y01/02/06 (December 17, 2002).

5 G.F. Knoll, Radiation Detection and Measurement, Second Edition, John-Wiley and Sons (1989).

6 H. Cember, Introduction to Health Physics, Second Edition, McGraw-Hill (1983).

7 J.R. Green, "Progress Report for the Enhancement of Radcalc: Isotope Database, Gamma Absorption Fractions, and G(H $\left.\mathbf{H}_{2}\right)$ Values,” WHC-SD-TP-RPT-014 (September 28, 1994).

8 U.S. Department of Energy (DOE), “CH-TRU Payload Appendices,” Rev. 1, U.S. Department of Energy, Carlsbad Field Office, Carlsbad, New Mexico (May 2005).

9 D.W. Vinson, N.E. Bibler, R.W. Deible, and R.L. Sindelar, "Evaluation of Hydrogen Generation from Radiolysis from Breached Spent Fuel," American Nuclear Society Annual Meeting (September 19, 2002).

10 S. Pauly, “Permeability and Diffusion Data," in Polymer Handbook, Fourth Edition, John Wiley \& Sons, Inc. (1999).

11 C.F. Jones, “Soil Samples,” email communication to C. Nichols (Thu Jun 07 12:52:59 2007).

12 Code of Federal Regulations, 10CFR71.

13 “Evaluated Nuclear Structure Data File” - A Computer File of Evaluated Experimental Nuclear Data Maintained by the National Nuclear Data Center, Brookhaven National Laboratory ENDF/B-VI. 